\title{
Article
}

\section{Adaptation of pharmaceutical excipients to FDM 3D printing for the fabrication of patient-tailored immediate release tablets}

Sadia, Muzna, Sośnicka, Agata, Arafat, Basel, Isreb, Abdullah, Ahmed, Waqar, Kelarakis, Antonios and Alhnan, Mohamed A

Available at http://clok.uclan.ac.uk/15754/

Sadia, Muzna, Sośnicka, Agata, Arafat, Basel, Isreb, Abdullah ORCID: 00000001-9939-6161, Ahmed, Waqar ORCID: 0000-0003-4152-5172, Kelarakis, Antonios ORCID: 0000-0002-8112-5176 and Alhnan, Mohamed A (2016) Adaptation of pharmaceutical excipients to FDM 3D printing for the fabrication of patient-tailored immediate release tablets. International Journal of Pharmaceutics, 513 (1-2). pp. 659-668. ISSN $0378-5173$

It is advisable to refer to the publisher's version if you intend to cite from the work. http://dx.doi.org/10.1016/j.jpharm.2016.09.050

For more information about UCLan's research in this area go to http://www.uclan.ac.uk/researchgroups/ and search for <name of research Group>.

For information about Research generally at UCLan please go to http://www.uclan.ac.uk/research/

All outputs in CLoK are protected by Intellectual Property Rights law, including Copyright law. Copyright, IPR and Moral Rights for the works on this site are retained by the individual authors and/or other copyright owners. Terms and conditions for use of this material are defined in the policies page. 


\title{
Adaptation of pharmaceutical excipients to FDM 3D printing for the fabrication of patient-tailored immediate release tablets
}

Muzna Sadiaa, Agata Sośnickaa, Basel Arafata, Abdullah Isreba, Waqar Ahmedb, Antonios Kelarakisc, Mohamed A Alhnan*

${ }^{a}$ School of Pharmacy and Biomedical Sciences, University of Central Lancashire, Preston, Lancashire, $U K$

${ }^{b}$ School of Medicine, University of Central Lancashire, Preston, Lancashire, UK

${ }^{c}$ School of Physical Sciences \& Computing, University of Central Lancashire, Preston, Lancashire, $U K$

\begin{abstract}
This work aims to employ fused deposition modelling 3D printing to fabricate immediate release pharmaceutical tablets with various model drugs. It investigates the addition of nonmelting filler to methacrylic matrix to facilitate FDM 3D printing and explore the impact of i) the nature of filler, ii) compatibility with the gears of the 3D printer and, and iii) polymer: filler ratio on the $3 \mathrm{D}$ printing process. A specially developed filament based on pharmaceutically approved methacrylic polymer (Eudragit E) and thermally stable filler, TCP (tribasic calcium phosphate) was optimised. Four model drugs (with different physicochemical properties were included into ready-to-use mechanically stable tablets with immediate release properties. Amongst the investigated fillers in this work, directly compressible lactose, spray-dried lactose and microcrystalline cellulose showed a level of degradation at $135^{\circ} \mathrm{C}$ whilst talc and TCP allowed consistent flow of the filament and a successful 3D printing of the tablet. Following the two thermal processes (hot melt extrusion (HME) and fused deposition modelling (FDM) 3D printing), drug contents were $94.22 \%, 88.53 \%, 96.51 \%$ and $93.04 \%$ for 5-ASA, captopril, theophylline and prednisolone respectively. XRPD indicated that a fraction of 5-ASA, theophylline and prednisolone remained in the crystalline form whilst captopril was in amorphous form. By combining the advantages of thermally stable pharmaceutically approved polymers and fillers, this unique approach provides a low cost production method for on demand manufacturing of individualised dosage forms.
\end{abstract}

*Corresponding author: MAlbedAlhnan@uclan.ac.uk 


\section{Introduction}

Advances in the field of pharmacogenomics have provided the impetus for personalised dosage forms to suit an individual patient's need (Ginsburg and Willard, 2009; Hamburg and Collins, 2010; Tremblay and Hamet, 2013). In the future it is highly likely that the trend will shift towards the fabrication of unit dosage forms closer to patients; at the point of dispensing, or even at the point of use. This is in line with current trends which encourage the provision of efficient outpatients' services which can be controlled digitally and remotely (McLean et al., 2013). The demand for versatile and adjustable manufacturing technologies that are capable of overcoming the rigidity and the high cost of traditional manufacturing methods of individualised oral tablets for a limited number of patients is also rising (Yang et al., 2016; Yu et al., 2015). Unlike conventional tablet compression methods, 3D Printing technologies are capable of fabricating small number of dosage forms, reduce the number of steps and experienced operators involved in manufacturing, and eliminate the need for designated and expensive facilities (Skowyra et al., 2015).

Three-dimensional (3D) printing technologies are set to revolutionise the individualisation of dosage forms at the point of dispensing or use (Sanderson, 2015). These highly attractive technologies produce 3-dimensional objects of virtually any shape under the control of a computer software. Powder based 3D printing was first adapted to fabricating tablets with immediate (Pyrce Lewis et al., 2011; Wang et al., 2006; Yu et al., 2007), delayed release profiles (Fuh et al., 1999). In late 2015, the FDA approved the first 3D printed fast-dissolving tablets for treatment of epilepsy, Spritam ${ }^{\circledR}$ (levetiracetam) (Aprecia, 2014; Yoo et al., 2014). However, the technology produces tablets of poor mechanical properties and surface imperfections (Katstra et al., 2000b; Pham and Gault, 1998; Yu et al., 2009). Powderspecialised facilities with potential wastage are less suitable for small-scale production in a community or hospital pharmacies (Huang et al., 2013).

Semi-solid Extrusion (EXT) 3D printing, has been explored recently for the fabrication of tablets using semi-solid starting materials through a syringe based tool-head. EXT 3D printing is capable of fabricating bilayer tablets (Khaled et al., 2014a) or polypills with different release profiles at room temperature (Khaled et al., 2015a, b). Nonetheless, the technology requires post-operating drying process and yields tablets of high friability (Katstra et al., 2000a; Khaled et al., 2014b). FDM 3D printing is an attractive platform because it offers mechanically stable 
printed structures (Pietrzak et al., 2015), with high resolution (30-200 $\mu \mathrm{m})$ (Goyanes et al., 2015a) and a ready-to-use printed objects from the printer platform with no additional postprocessing steps (Goyanes et al., 2015b; Skowyra et al., 2015). Due to the expiration of patents of this technology and the availability of low cost FDM printers, this technology is likely to be widely utilized by a large number of consumers.

The potential of FDM 3D printing incorporating drugs into commercially available filaments (Goyanes et al., 2014a; Goyanes et al., 2014b; Goyanes et al., 2015b; Skowyra et al., 2015) has been explored previously. Nonetheless, all those studies highlighted several challenges involved in employing printing technique for pharmaceutical applications. The use of elevated temperatures $\left(185-220^{\circ} \mathrm{C}\right)$ and limited drug loading (0.063-9.5\% w/w (Goyanes et al., 2014a; Goyanes et al., 2014b; Goyanes et al., 2015b; Skowyra et al., 2015) renders it less suitable for many drugs particularly thermo-labile ones. FDM 3D printing has been also restricted to a number of biodegradable thermoplastic polymers such as polylactic acid (PLA) (Sandler et al., 2014) and polyvinyl alcohol (PVA) (Goyanes et al., 2014a; Goyanes et al., 2014b; Goyanes et al., 2015b; Skowyra et al., 2015) in comparison to a wide variety of choices for conventional tabletting. Despite the attractive properties of PVA (Morita et al., 2000) and PLA(Hamad et al., 2016), the use of high polymer ratio in combination with the need for high molecular weight of the polymers generates polymeric matrices with limited porosity, thus resulting in extended drug release patterns (Goyanes et al., 2014a; Goyanes et al., 2014b; Goyanes et al., 2015a; Goyanes et al., 2015b; Sandler et al., 2014; Skowyra et al., 2015).

Approximately $40 \%$ of drug delivery products are taken orally and $70 \%$ of these are immediate release formulations (GBIResearch, 2012; Marketsandmarkets, 2013). Hence, it is of great interest to adapt FDM 3D printing to pharmaceutical materials and different drug molecules for immediate release of the final product. Eudragit EPO is a robust drug delivery carrier with taste masking, moisture protection and good mechanical properties (Shishu et al., 2010). The branched nature of the polymer however gives it a lower glass transition temperature ( $\mathrm{Tg}$ ) value compared to linear copolymers (Tapan Parikh, 2014). The ability to adapt polymers with such low Tg values to FDM 3D printing is a major challenge. We have reported employing Eudragit EPO for production of immediate release theophylline tablet (Pietrzak et al., 2015). However, the suitability of this polymer to fabricate immediate release tablets when loaded with molecules of different physicochemical properties is still not established. In this paper, we introduced the addition of a non-melting filler to methacrylic matrix to facilitate FDM 3D 
printing and assessed the impact of: i) the nature of filler, ii) compatibility with the gears of the 3D printer and, and iii) polymer: filler ratio. Furthermore, we exploited the optimised filament from this approached and utilized it as a generic platform to accommodate four model drugs with acidic (5-ASA and captopril), basic (theophylline) and neutral (prednisolone) nature and different melting points. We have also evaluated their stability during the thermal processes and the quality of resultant 3D printed tablets.

\section{Materials and methods}

\subsection{Materials}

Theophylline $\left(\mathrm{T}_{\mathrm{m}}=273^{\circ} \mathrm{C}\right)$ was purchased from Arcos (UK). Eudragit EPO was donated by Evonik Industries (Darmstadt, Germany). Triethyl citrate (TEC), tri-Calcium phosphate (TCP), talc, 5-ASA $\left(\mathrm{T}_{\mathrm{m}}=283^{\circ} \mathrm{C}\right)$, captopril $\left(\mathrm{T}_{\mathrm{m}}=103^{\circ} \mathrm{C}\right)$ and prednisolone $\left(\mathrm{T}_{\mathrm{m}}=230^{\circ} \mathrm{C}\right)$ were supplied by Sigma-Aldrich (UK). Scotch blue painter's tape $50 \mathrm{~mm}$ was supplied by $3 \mathrm{M}$ (Bracknell, UK). Spray-dried lactose, directly compressible lactose Ludipress ${ }^{\circledR}$ and microcrystalline cellulose (MMC) Avicel ${ }^{\circledR}$ were purchased from FMC biopolymers (UK).

\subsection{Preparation and optimisation of filaments}

The impact of adding a non-melting component to the methacrylic matrix at different ratios using different pharmaceutical fillers on the production of compatible filament was assessed. The filament was considered compatible with the gears of the FDM 3D printer's head if it allows continuous flow from the hot nozzle (i.e. without breaking within the gears of the printer's head (brittle filaments) or bending between the gears and the hot nozzle (flexible filament).

The screening of commonly used fillers in tablet manufacturing was conducted to explore their suitability with the immediate release polymer Eudragit E. Additives examined in the study were; microcrystalline cellulose (MCC), talc, tri-calcium phosphate (TCP) as well as spray dried (SD) and directly compressible (DC) lactose.

To assess the suitability of the different fillers, filaments with Eudragit EPO (plasticised by 6.5\% w/w TEC) and different fillers at ratio 50:50 were first utilised using HME as specified below. In order to optimise the flexibility of Eudragit EPO matrix, different TEC (plasticiser) concentrations were scanned at 5\%,6\%, 6.5\% and $10 \%$ of polymer weight and filaments were produced at 50:50 ratio of Eudragit EPO matrix and a non-melting filler (TCP). To assess the 
influence of concentration of non-melting filler, different ratios of TCP: Eudragit EPO matrix (containing 6.5\% TEC as plasticiser) ratios were screened: 0:100, 20:80, 40:60, 50:50 and 60:40. An optimised ratio of Eudragit E: TEC: TCP (46.75:3.25:50) were concluded based on the filler's stability, compatibility with the gears of the printer head and rheology of the filament at the printing temperature (see Results and discussion section). Later, the optimised ratio was employed to produce drug loaded filaments for 4 model drugs (5-ASA, captopril, prednisolone or theophylline) [ratio Eudragit E: TEC: TCP: drug (46.75:3.25:37.5:12.5)], where the drug was considered as a replacement for a portion of the filler.

Approximately $10 \mathrm{~g}$ of materials was accurately weighed and added gradually to counter flow twin-screw hot melt extruder, HAAKE MiniCTW (Karlsruhe, Germany). To allow homogeneous distribution of the powders, the molten mass was mixed in the extruder for at least 5 min prior to extrusion. The specific temperature of initial feeding and extrusion for the filament were 100 and $90{ }^{\circ} \mathrm{C}$ respectively. A torque control of $0.8 \mathrm{Nm}$ was used to extrude out the filaments. Filaments were stored in sealed plastic bags at room temperature before 3D printing.

\subsection{Design and printing of tablets}

Tablets were constructed with the pre-prepared filaments using a commercial FDM 3D printer equipped with $0.4 \mathrm{~mm}$ nozzle size. The templates used to print the tablets were designed in caplet shape using Autodesk ${ }^{\circledR}$ 3ds Max ${ }^{\circledR}$ Design 2012 software version 14.0 (Autodesk, Inc., USA). The design was saved in a stereolithography (.stl) file format and was imported to the 3D printer's software, MakerWare Version 3.9.1.1143 (Makerbot Industries, LLC., USA). Tablets were printed using modified settings of the software for PLA: as follows: type of printer: Replicator 2X; type of filament: PLA; resolution: standard; speed of extruder $90 \mathrm{~mm} / \mathrm{s}$ while extruding and $150 \mathrm{~mm} / \mathrm{s}$ while traveling; infill: 100\%; height of the layer: $200 \mu \mathrm{m}$. No supports or rafts were utilized. The temperatures for the nozzle and build plate of the $3 \mathrm{D}$ printer were $135^{\circ} \mathrm{C}$ and $60{ }^{\circ} \mathrm{C}$ respectively. Blue Scotch painter's tape was applied to the build platform to facilitate the adherence of the printed object during FDM 3D printing. A series of tablets were printed individually in the following dimensions: Length $\times$ Width $\times$ Height $(12 \times 4.59 \times 4.71 \mathrm{~mm})$.

\subsection{Thermal analysis}

Samples of (raw materials, extruded filaments and printed tablets) were characterised using differential scanning calorimetry (DSC) and thermogravimetric analysis (TGA). For DSC 
analysis, a differential scanning calorimeter DSC Q2000 (TA Instruments, Elstree, Hertfordshire, UK) with a heating rate of $10{ }^{\circ} \mathrm{C} / \mathrm{min}$ was used. Samples were heated to $100{ }^{\circ} \mathrm{C}$ for 5 min to exclude the effect of humidity then cooled to $-20{ }^{\circ} \mathrm{C}$. This was followed by a heat scan from $-20{ }^{\circ} \mathrm{C}$ to $300{ }^{\circ} \mathrm{C}$. Analysis was carried out under a purge of nitrogen $(50 \mathrm{~mL} / \mathrm{min})$. The data was analysed using TA 2000 analysis software. Standard $40 \mu \mathrm{L}$ TA aluminium pans and pin-holed lids were used with an approximate sample mass of $5 \mathrm{mg}$. All measurements were carried out in triplicates.

For TGA analysis, raw materials, model drugs, extruded filaments and 3D printed tablets were measured using a TGA/SDTA851e Mettler Toledo (Leicester, UK). Samples (5 mg) were placed in $40 \mu \mathrm{L}$ aluminium pans and were then heated from 25 to $500^{\circ} \mathrm{C}$ using $10^{\circ} \mathrm{C} / \mathrm{min}$ as a heating rate. The thermal decomposition (or degradation) profile was analysed using STARE software version 9.00. The experiments were carried out under nitrogen gas flow of $50 \mathrm{~mL} / \mathrm{min}$. All measurements were carried out in triplicates.

\section{$2.5 X$-ray Powder diffractometry (XPRD)}

A powder X-ray diffractometer, D2 Phaser with Lynxeye (Bruker, Germany) was used to assess the physical form of model drugs in Eudragit E, TCP, Eudragit E:TEC filament, blank and drug-loaded filaments, and 3D printed tablets. Samples were scanned from 2Theta $(2 \theta)=$ $5^{\circ}$ to $50^{\circ}$ using $0.01^{\circ}$ step width and a 1 second time count. The divergence slit was $1 \mathrm{~mm}$ and the scatter slit $0.6 \mathrm{~mm}$. The wavelength of the X-ray was $0.154 \mathrm{~nm}$ using $\mathrm{Cu}$ source and a voltage of $30 \mathrm{kV}$. Filament emission was $10 \mathrm{~mA}$ using a scan type coupled with a two theta/theta scintillation counter over $30 \mathrm{~min}$.

\subsection{Rheological properties of filament}

The rheological properties of TCP filaments were studied using an AR2000 rheometer (TA instruments, USA), equipped with parallel plate geometry (diameter $25 \mathrm{~mm}$ ). The strain $(\varepsilon)$ sweep tests were conducted at $135^{\circ} \mathrm{C}$, at an angular frequency of $\omega=10 \mathrm{rad} / \mathrm{s}$.

\subsection{Scanning Electron Microscopy}

The surface morphology of the filaments and the printed tablets was assessed using a Quanta200 SEM microscope at $20 \mathrm{kV}$. All samples for SEM visualisation were placed on a metallic stub and gold plated using a JFC-1200 Fine Coater (Jeol, Tokyo, Japan). Photographs of the tablets were captured with a Canon EOS-1D Mark IV (Canon Ltd, Japan). 


\subsection{Characterisation of the tablets properties}

The hardness of 6 tablets was measured using a TBH 200 (Erweka GmbH, Heusenstamm, Germany). The mean crushing strength was determined, whereby an increasing force was applied to the tablet until it was fractured or deformed.

In order to assess the friability of the tablets, 20 tablets were randomly selected, weighed and placed in a friability Tester Erweka type TAR 10 (Erweka GmbH, Heusenstamm, Germany) and the drum was then rotated at $25 \mathrm{rpm}$ for $4 \mathrm{~min}$. The tablets were reweighed and the differences in weight were calculated and displayed as a percentage of the original sample weight. In order to assess weight uniformity, 10 tablets were randomly selected and weighed. The average weights were measured and the percentage deviation of the individual tablets from mean was determined.

To assess the impact of both HME and FDM 3D printing on drug contents, 3 tablets from each formulation, were randomly selected and weighed. Tablets were then individually placed in a $1000 \mathrm{~mL}$ volumetric flask containing $0.1 \mathrm{M} \mathrm{HCl}$ and sonicated for 2 hours. The solution were filtered through $0.22 \mu \mathrm{m}$ Millex-GP syringe filters (Merck Millipore, USA) and prepared for HPLC analysis.

Drug contents in relevant samples were assessed using an Agilent UV-HPLC 1260 series (Agilent Technologies, Inc., Germany) equipped with XTerra RP 18 column (150 x $4.6 \mathrm{~mm}$, $5 \mu \mathrm{m}$ particle size) (Waters, Ireland) for theophylline and Kinetex C18 column $(100 \times 2.1 \mathrm{~mm}$, particle size $2.6 \mu \mathrm{m}$ ) (Phenomenex, Torrance, USA) for 5-ASA, prednisolone and captopril at temperature $26^{\circ} \mathrm{C}$. The mobile phase was (acetonitrile: water adjusted to $\mathrm{pH} 3$ with orthophosphoric acid, at ratios 40:60, 90:10 and 80:20 for 5-ASA, prednisolone and captopril and a flow rate of $0.5 \mathrm{~mL} / \mathrm{min}$. For theophylline, the mobile phase was composed of ammonium acetate buffer, methanol and acetonitrile (86:7:7) at a flow rate $1 \mathrm{~mL} / \mathrm{min}$. The injection volume was $20 \mu \mathrm{L}$ and a stop time was 10 min per sample.

In vitro disintegration and drug release studies. Tablet disintegration was carried out using an Erweka ZT220 disintegration testing apparatus (Erweka GmbH, Heusenstamm, Germany). Six tablets were randomly selected, weighed and each placed in a basket rack assembly having six cylinders and the tablets were covered with discs. The basket rack assembly was then immersed into a beaker containing $0.1 \mathrm{M} \mathrm{HCl}$ at $37^{\circ} \mathrm{C}$. The exact time for all tablets to fully leave the mesh was visually noted. 
In vitro drug release studies was investigated using a USP II Erweka DT600 dissolution tester (Erweka GmbH, Heusenstamm, Germany). Three tablets were randomly selected and individually placed in the dissolution vessels each containing $900 \mathrm{~mL}$ of $0.1 \mathrm{M} \mathrm{HCl}$ at $50 \mathrm{rpm}$ and $37 \pm 0.5{ }^{\circ} \mathrm{C}$. Aliquots $(4 \mathrm{ml})$ were manually collected using $5 \mathrm{ml}$ Leur-Lock syringes at 0,5 , 10, 15, 20, 25, 30, 40, 50 and 60 minutes time intervals and filtered through a Millex-HA 0.45 $\mu \mathrm{m}$ filter. Each aliquot withdrawn was replaced with $4 \mathrm{~mL}$ of $0.1 \mathrm{M} \mathrm{HCl}$. The absorbance of the samples were finally measured using a Jenway UV spectrophotometer (Bibby Scientific Ltd, UK) at $\lambda \max$ of 232, 204, 247 and $272 \mathrm{~nm}$ for 5-ASA, captopril prednisolone and theophylline respectively.

\section{Statistical analysis}

One-way ANOVA was employed using SPSS Software (22.0.0.2) to analyse the results. Differences in results of $p<0.05$ were considered to be significant.

\section{Results and discussion}

Fig. 1 illustrates the production of methacrylic tablets via FDM 3D printing with a focus on immediate release properties. The process involves; firstly, the development of drug-loaded filaments via processing a physical mixture of melting and non-melting components of the polymer, drug and excipients through $\mathrm{HME}$ at $100{ }^{\circ} \mathrm{C}$ (Fig. 1a); secondly the utilization of computer to design capsule-shaped tablets (Fig. 1b); thirdly, feeding the drug-loaded filaments into an FDM based 3D printer (Fig. 1c) and finally, the fabrication of 3D printed tablets at 135 ${ }^{\circ} \mathrm{C}$ (Fig. 1d). 


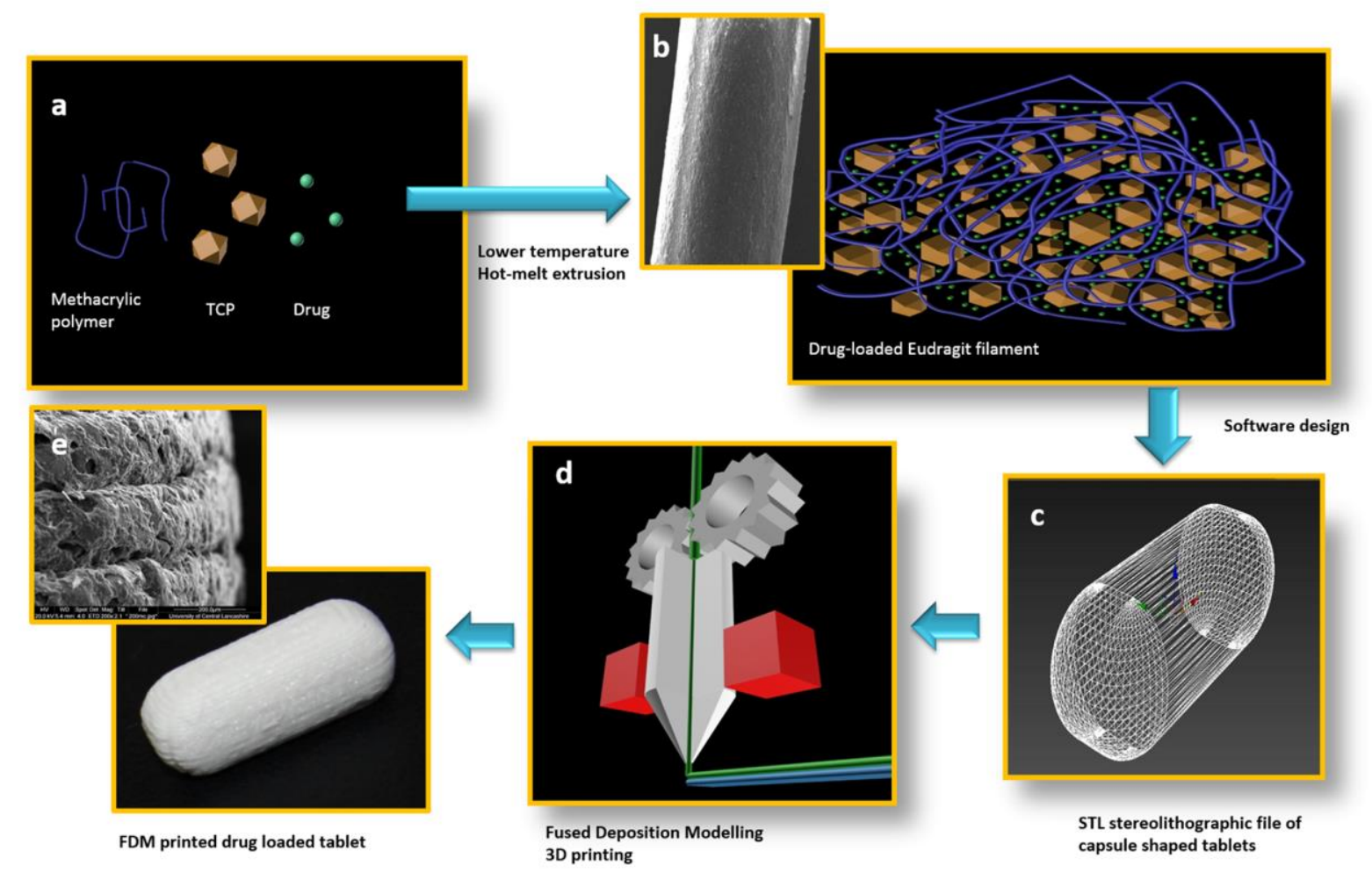

Fig. 1. Schematic illustration of the fabrication of immediate release 3D-printed tablet. (A) Materials mixture (drug, methacrylic polymer and TCP) are processed through HME to produce (B) a uniform filament. (C) Stereolithographic file is created via CAD software and (D) benchtop FDM 3D printer is used to (E) fabricate drug loaded immediate release tablet.

Initially filament based only on Eudragit EPO was examined. Although it was possible to extrude this filament from the printer nozzle, a collapsed structure was yielded with poor features and deformable build. Such a behaviour is related to the branched nature of the methacrylic polymer that gave a lower $(\mathrm{Tg})$ value compared to linear copolymers (Tapan Parikh, 2014). During FDM 3D printing, filaments passing through a heated nozzle are turned into semi-solids before solidifying to form 3D printed structures at room temperature. One solution is to add a component with a higher melting than the operating temperature of HME and FDM 3D printing. Several pharmaceutical fillers were screened for suitability of HME filament formulation and FDM 3D printing. DC and SD lactose types as well as MCC showed poor flow during FDM 3D printing and resulted in discoloured and incomplete printed structures. TGA studies (Fig. 2a) elucidated the thermal degradation of MCC following evaporation of MCC bonded water and the degradation of the cellulose skeleton $\left(>310{ }^{\circ} \mathrm{C}\right)$ (Huang, 2012). Both DC and SD lactose suffered a weight reduction above $100^{\circ} \mathrm{C}$ due to water loss followed by lactose backbone degradation $\left(>240{ }^{\circ} \mathrm{C}\right) . \mathrm{TCP}$ and talc appeared stable as 
supported by the TGA and demonstrated their thermal stability at temperatures $>250{ }^{\circ} \mathrm{C}$. This can be correlated to their high melting points $\left(>1000^{\circ} \mathrm{C}\right)$ (Enderle et al., 2005).

a

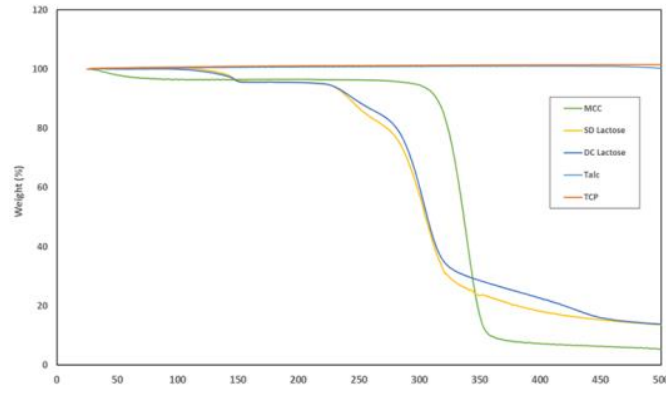

c

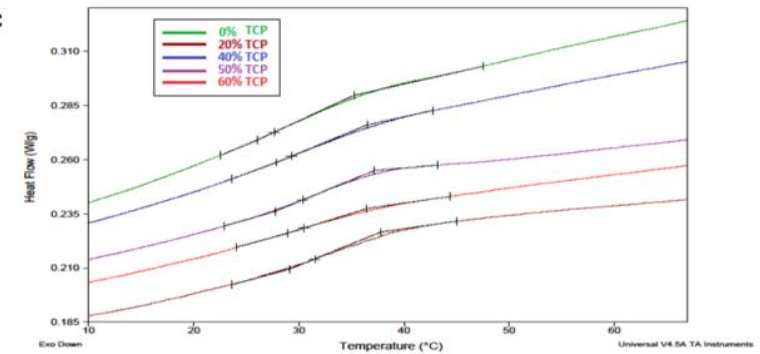

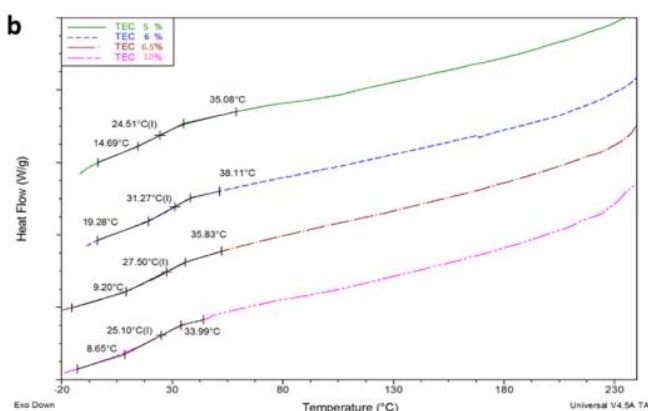

b

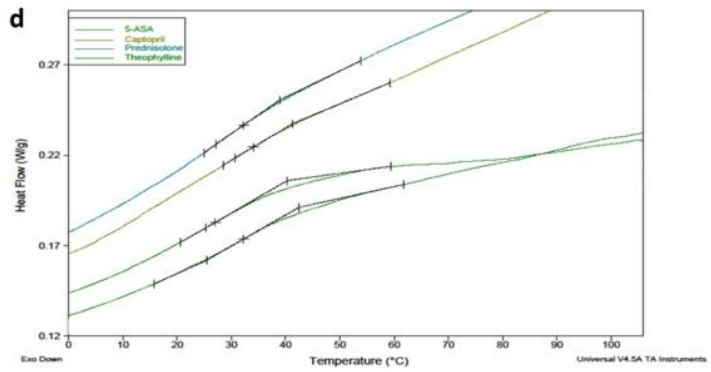

Fig. 2. Thermal analysis of Eudragit EPO based 3D printing filaments. (A) Thermal degradation profiles for different fillers screened for suitability with Eudragit EPO, (B) DSC thermograph for different plasticizer concentrations incorporated in Eudragit EPO filament, (C) DSC thermograph for different TCP concentrations (non-melting component) incorporated in the Eudragit EPO filament (containing $6.5 \%$ TEC as plasticiser) and (D) DSC thermograph of different 3D printed tablets containing the model drugs; 5-ASA, captopril, prednisolone or theophylline.

While both TCP and talc proved to be suitable thermostable fillers, it was decided to focus on TCP as a model filler. Thereafter, the level of plasticity of filament was optimised by modifying the concentration of the plasticizer (TEC) 5-10\% yielding filaments of Tg range of 29.7- 46.5 ${ }^{\circ} \mathrm{C}$ (Fig. 2b). While all the range facilitated the production of the filaments, poor flow of the filament were achieved at 5\% and $10 \%$ due to frequent breakage of the brittle filament or poor pressure on the nozzle of the excessively flexible filament during 3D printing, respectively.

The influence of non-melting component on the structure, $\mathrm{Tg}$ and rheological behaviour of the filament has been studied. SEM images showed that the extruded $(1.75 \mathrm{~mm})$ filament of Eudragit EPO (TCP-free) had a smooth surface and consistent cross sectional structure (Fig. 3a). However, it proved unsuitable for 3D printing process. Upon the addition of increasing concentrations of TCP, the surface of extruded filaments $(200 \mu \mathrm{m})$ appeared rough with voids and irregular pores between layers (Fig. 3b-e). The roughness and density of voids was also 
found to increase at higher percentages of TCP incorporated into the formulae. DSC thermographs on the other hand (Fig. 2c) revealed that the glass transition temperature ( $\mathrm{Tg}$ ) of polymeric matrix was not affected significantly by the incorporation of TCP at all of its ratios $(0-60 \%)(p>0.05)$ and the Tg remained approximately $30{ }^{\circ} \mathrm{C}$. This suggests that TCP particles remained suspended in Eudragit EPO matrix with minimal interference on the $\mathrm{Tg}$ of the methacrylic filament.
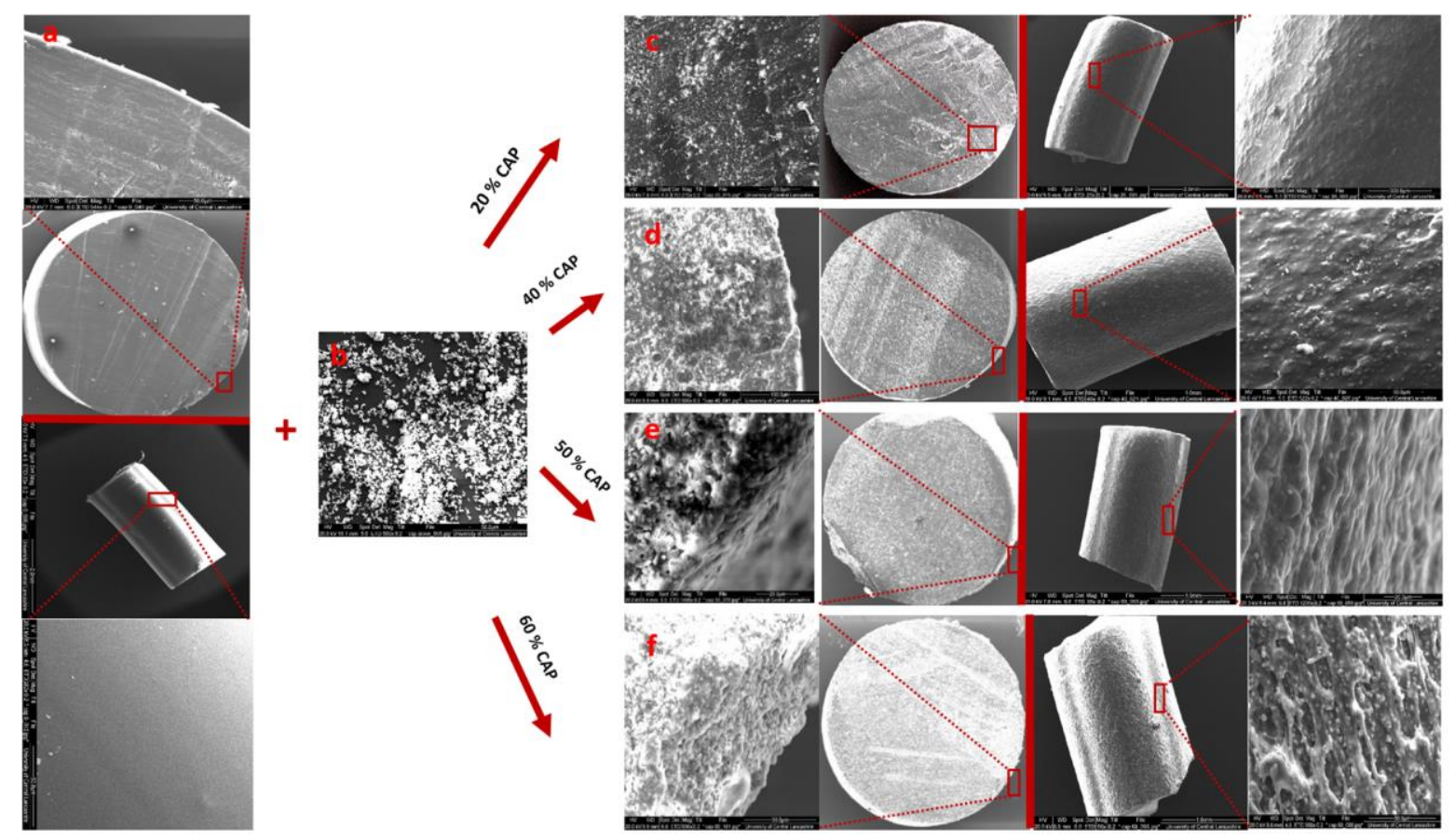

Fig. 3. Impact of TCP concentration on the morphology of Eudragit EPO filaments; (a) SEM images of filaments with no TCP, (b) SEM image of TCP alone and (c-f) SEM images of filament incorporating TCP at a ratio of $20,40,50$ or $60 \%$ respectively.

The filament behaviour within the high temperature nozzle of the 3D printer could be related to the rheological behaviour of the filament at elevated temperatures. Fig. 4 compares the rheological properties of the polymer matrices. All filaments exhibited a predominantly viscous character with $G^{\prime}<G^{\prime \prime}$ and the introduction of TCP was found to monotonically enhance the viscoelastic behaviour, as expected for filled polymeric systems (Yurekli et al., 2001). At high deformations all systems deviated from the linear viscoelastic region, exhibiting strain thinning. The critical strain amplitude for strain thinning systematically decreases with filler loading, consistent with general trends established for composites and nanocomposites materials (Yurekli et al., 2001). To that end, the $60 \% \mathrm{w} / \mathrm{w}$ TCP filament can withstand a maximum stress value of $21 \mathrm{kPa}$ (at $\gamma=2$ ) compared to $45 \mathrm{kPa}$ (at $\gamma=18), 50 \mathrm{kPa}$ (at $\gamma=29$ ) and $41 \mathrm{kPa}$ (at $\gamma=44$ ) for the $50 \%, 40 \%$ and $0 \% \mathrm{w} / \mathrm{w}$ TCP filament, respectively (Supplementary 
data, Appendix A, Fig. S1). This indicates that for FDM 3D printing the filament must withstand the stress exerted by the printer gears while having a considerably high viscosity capable of solidifying uniformly to withstand increasing weight of next layer during the printing process. Due to these findings a TCP ratio of $50 \%$ was used thereafter during the study.

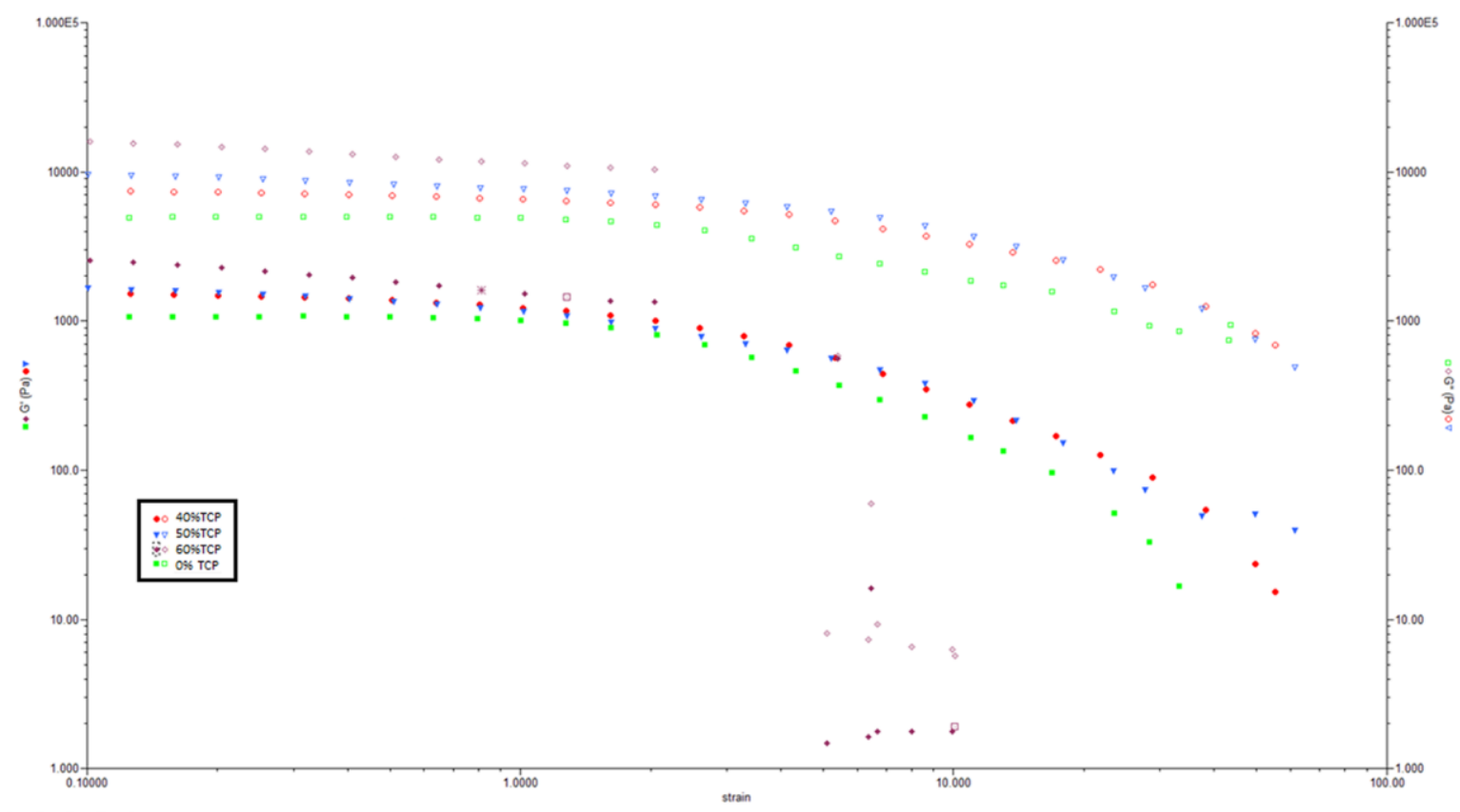

Fig. 4. Storage $\left(\mathrm{G}^{\prime}\right)$ and loss $\left(\mathrm{G}^{\prime \prime}\right)$ moduli of $\mathrm{CAP}$ based filaments as a function of the strain $\left(\mathrm{T}=135^{\circ} \mathrm{C}\right.$, $\left.\omega=10 \mathrm{rad} \cdot \mathrm{s}^{-1}\right)$.

The printing temperature in this study $\left(135^{\circ} \mathrm{C}\right)$ is noticeably lower than those recommended by $3 \mathrm{D}$ printer manufacturer $\left(230^{\circ} \mathrm{C}\right)$ (Makerbot, 2013), hence making printing via bridging $\mathrm{HME}$ with FDM 3D printing suitable for a wider spectrum of materials.

In order to prove the suitability of this model filament for different drug candidates, four model drug molecules with different physicochemical properties; 5-ASA, captopril, prednisolone and theophylline were incorporated in the formulation at a concentration of $12.5 \% \mathrm{w} / \mathrm{w}$.

DSC thermographs indicated that drugs had minor plasticizing effect on the filaments. However, the thermoplastic behaviour of Eudragit EPO was not altered significantly at the loadings studied (Fig. 2d). The incorporation of the drugs into the filaments did not hinder the FDM 3D printing process and caplets were successfully fabricated from all drug-loaded filaments. 

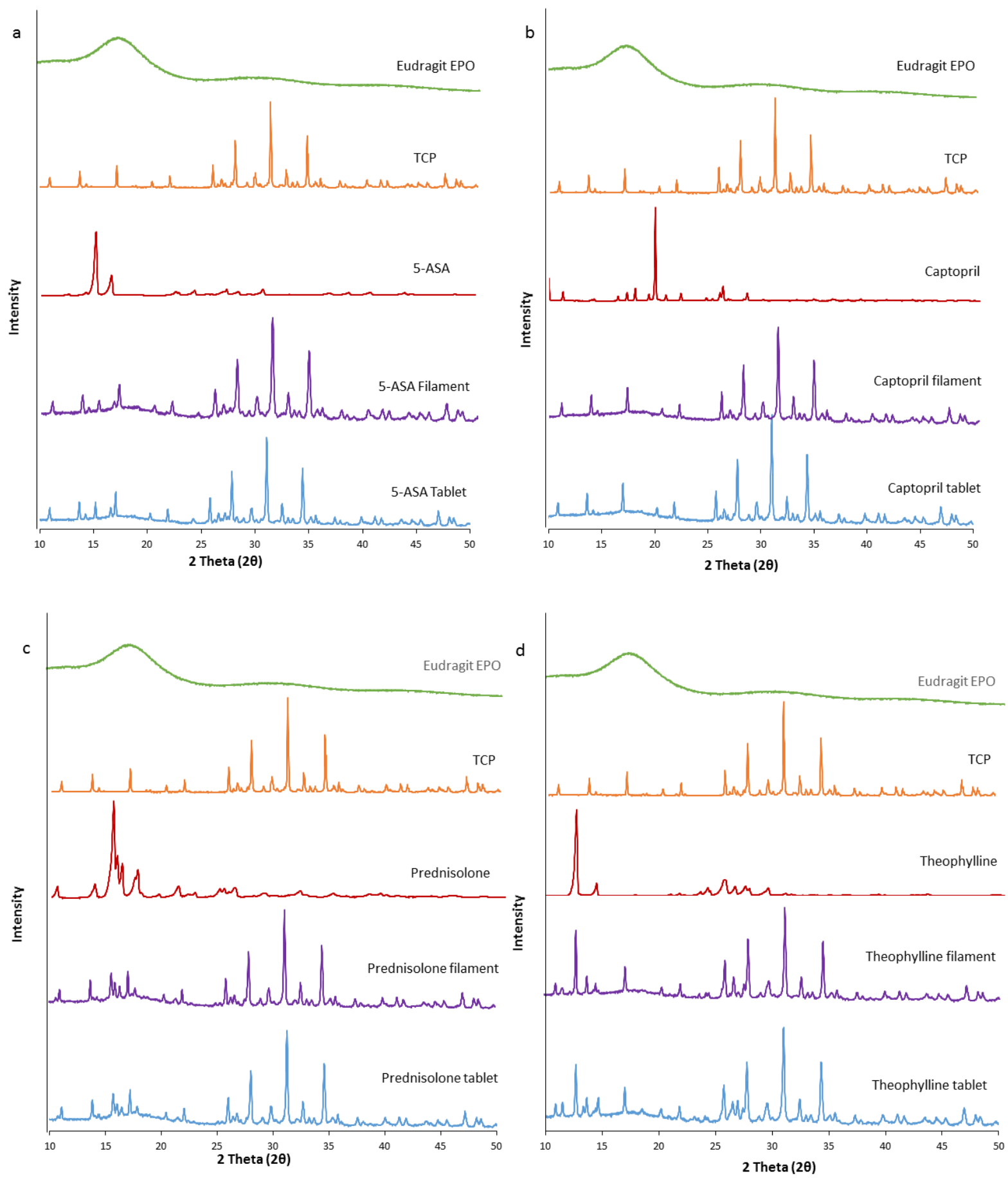

Fig. 5. XRPD patterns of Eudragit EPO, TPC, model drugs and drug loaded filaments and 3D printed tablets for a) 5-ASA, b) captopril, c) prednisolone and d) theophylline.

XRPD patterns confirmed the amorphous nature of Eudragit EPO whilst TCP remained crystalline across all the tested samples. XRPD patterns of both HME produced filaments and $3 \mathrm{D}$ printed tablets indicated the presence of intensity peaks at $(2 \theta)=7.9,15$ (Andrews et al., 2008; Bruce et al., 2005) for 5-ASA, $(2 \theta)=14.7,17.6$ for prednisolone (Nishiwaki et al., 2009; Sabzevari et al., 2013) and $(2 \theta)=7,12$ (Liu et al., 2007) for theophylline. This suggests that a 
fraction of these drugs remained in the crystalline form in filament and 3D printed tablets. In case of captopril, the absence of peaks at $(2 \theta)=10,12$ and 20 (Khaled et al., 2015c) in the extruded filament as well as the 3D printed tablet indicated that the majority of captopril remained amorphous. It is possible that the use of a HME and FDM temperatures (100 and 135 ${ }^{\circ} \mathrm{C}$ respectively) close or above the melting point of captopril $\left(103{ }^{\circ} \mathrm{C}\right)$ resulted in complete melting of the drug and yielded a non-crystalline filament matrix.

The weight uniformity, drug content and friability of the caplets produced were evaluated (Table 1). HPLC analysis indicated that HME process is the major degradation step rather than the FDM 3D printing step. It is possible that during filament preparation the model drugs are exposed to relatively high temperature $\left(100{ }^{\circ} \mathrm{C}\right.$ ) for much longer period of time (up to $10 \mathrm{~min}$ ) than that in hot nozzle of the 3D printer (fraction of a second) . The drug contents was $>93 \%$ for 3D printed tablets of theophylline, prednisolone and 5-ASA. In case of captopril, its content was lower (88\%), which might be related to drug degradation during HME process and FDM $3 \mathrm{D}$ printing. This was confirmed with a reduction in captopril tablet weight at $135{ }^{\circ} \mathrm{C}$ as established in TGA data (Fig. 6). Although the weights of the different formulations were found to vary slightly between formulations, there were no significant differences in the dimensions of the printed tablets ( $p>0.05$ ) (Table 1). Tablets were designed in caplet shape to enhance patient compliance (Overgaard et al., 2001; Schiele et al., 2012). They were made of stacked $200 \mu \mathrm{m}$ thick layers as it can be observed with SEM images (Fig. 7). The dose of the caplets can be adjusted using the software by modifying the volume of the printed drug delivery system (Pietrzak et al., 2015). Thus, FDM 3D printing is a highly attractive in modifying the dose to suit patients' individual needs. 

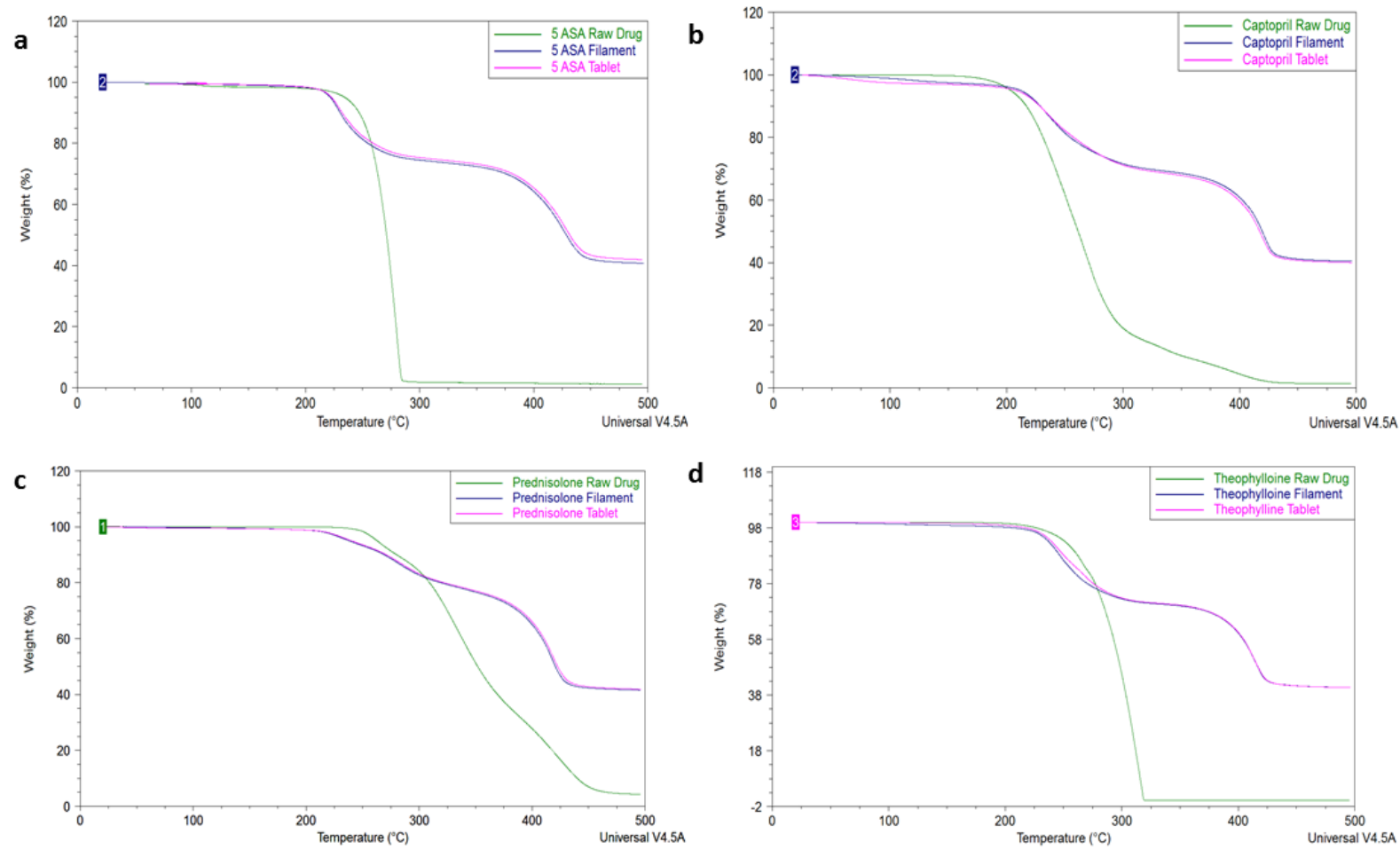

Fig. 6. Thermal degradation profiles for the used model drugs, drug loaded filament and 3D printed tablet; a) 5ASA, b) captopril, c) prednisolone and d) theophylline.

Table 1. Summary of weight uniformity, drug content, friability, disintegration time and the dimensions of the different 3D printed tablets.

\begin{tabular}{|c|c|c|c|c|c|c|c|c|}
\hline \multirow[t]{2}{*}{ Drug } & \multirow{2}{*}{$\begin{array}{l}\text { Weight } \\
\text { Uniformity } \\
\text { +SD (mg) }\end{array}$} & \multicolumn{2}{|c|}{ Drug content } & \multirow{2}{*}{$\begin{array}{l}\text { Friability } \\
(\%)\end{array}$} & \multirow{2}{*}{$\begin{array}{l}\text { Disintegration } \\
\text { time (min) }\end{array}$} & \multicolumn{3}{|l|}{ Dimensions } \\
\hline & & Filament & Tablet & & & $\mathbf{L}(\mathbf{m m})$ & $\mathbf{W}(\mathbf{m m})$ & $\mathbf{H}(\mathrm{mm})$ \\
\hline 5-ASA & $203.6 \pm 16.7$ & $94.61 \pm 1.42$ & $94.22 \pm 1.15$ & 0 & $11.72 \pm 0.12$ & $3.91 \pm 0.12$ & $4.90 \pm 0.03$ & $11.72 \pm 0.12$ \\
\hline Captopril & $226.1 \pm 18.4$ & $88.15 \pm 0.78$ & $88.53 \pm 0.02$ & 0 & $11.71 \pm 0.22$ & $4.105 \pm 0.25$ & $4.86 \pm 0.12$ & $11.71 \pm 0.22$ \\
\hline Prednisolone & $232.6 \pm 17.7$ & $97.18 \pm 0.61$ & $96.51 \pm 1.38$ & 0 & $11.63 \pm 0.14$ & $4.21 \pm 0.13$ & $4.90 \pm 0.12$ & $11.63 \pm 0.14$ \\
\hline Theophylline & $194.8 \pm 10.8$ & $95.04 \pm 1.52$ & $93.04 \pm 0.55$ & 0 & $11.69 \pm 0.18$ & $4.00 \pm 0.34$ & $4.92 \pm 0.18$ & $11.69 \pm 0.18$ \\
\hline
\end{tabular}



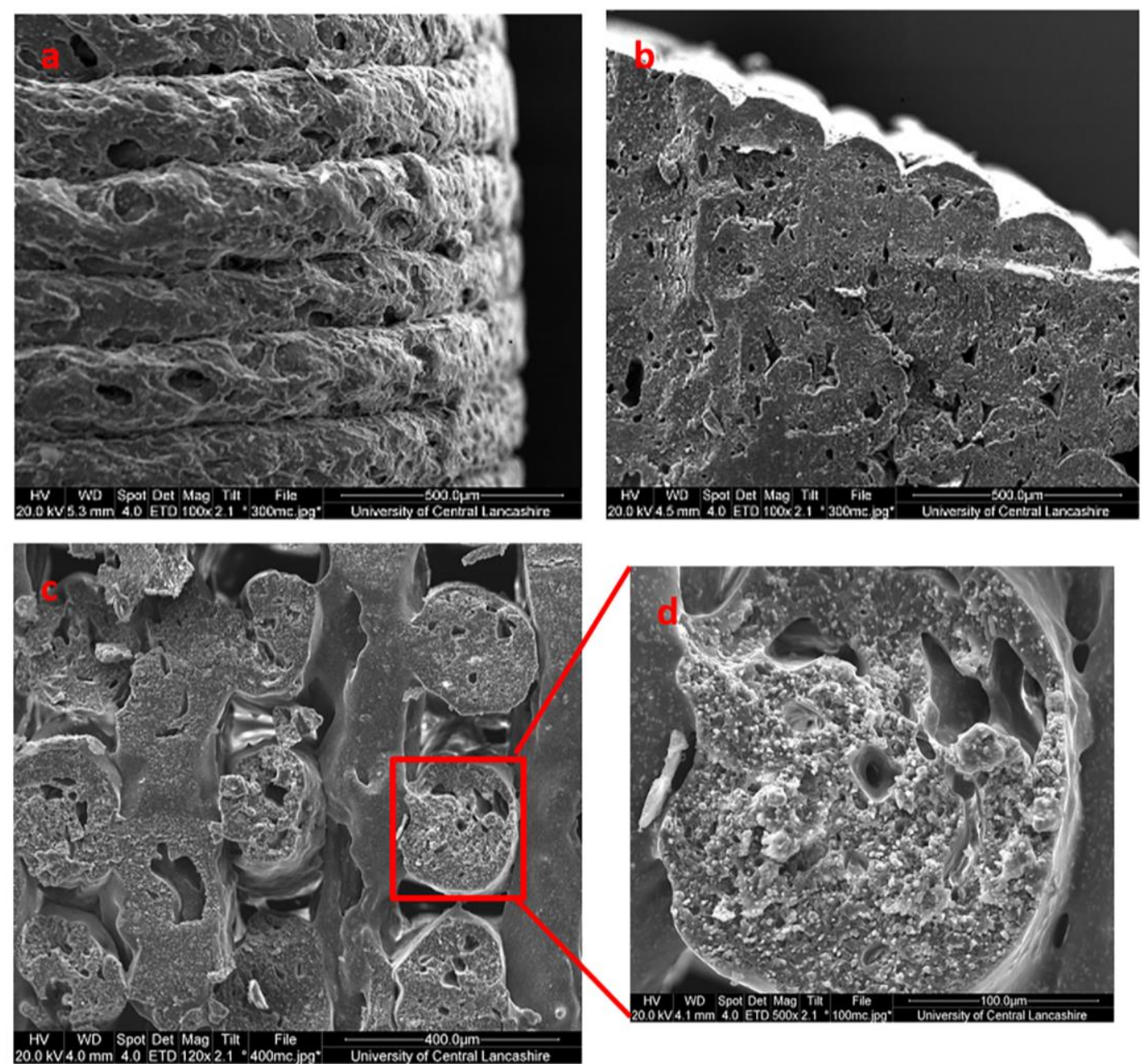

Fig. 7. SEM images of 3D printed tablets containing theophylline; (A) surface morphology (B-D) crosssections.

Analysis of the drug content of 3D printed tablets demonstrated the capability of the bench-top FDM printer in fabricating tablets with acceptable in-batch drug content variations analogous to findings of Pietrzak et al. (2015). (Table 1). The friability revealed no variations and was demonstrated to be $0 \%$ for all the formulation. Unlike tablets generated from other 3D printed technologies such as EXT (Khaled et al., 2014a) and powder-based 3D printing (Katstra et al., 2000b; Yu et al., 2009), the friability of tablets generated using via FDM 3D printing tends to be very low or even zero (Goyanes et al., 2014a; Goyanes et al., 2015c; Pietrzak et al., 2015). Such mechanical resistant was also observed in metal/polymer composite filaments (Hwang et al., 2014) and gives an indication on the capability of FDM 3D printing in unit fabrication without additional post manufacturing processing. This makes the technology highly suitable for on-demand dosage form manufacturing. 

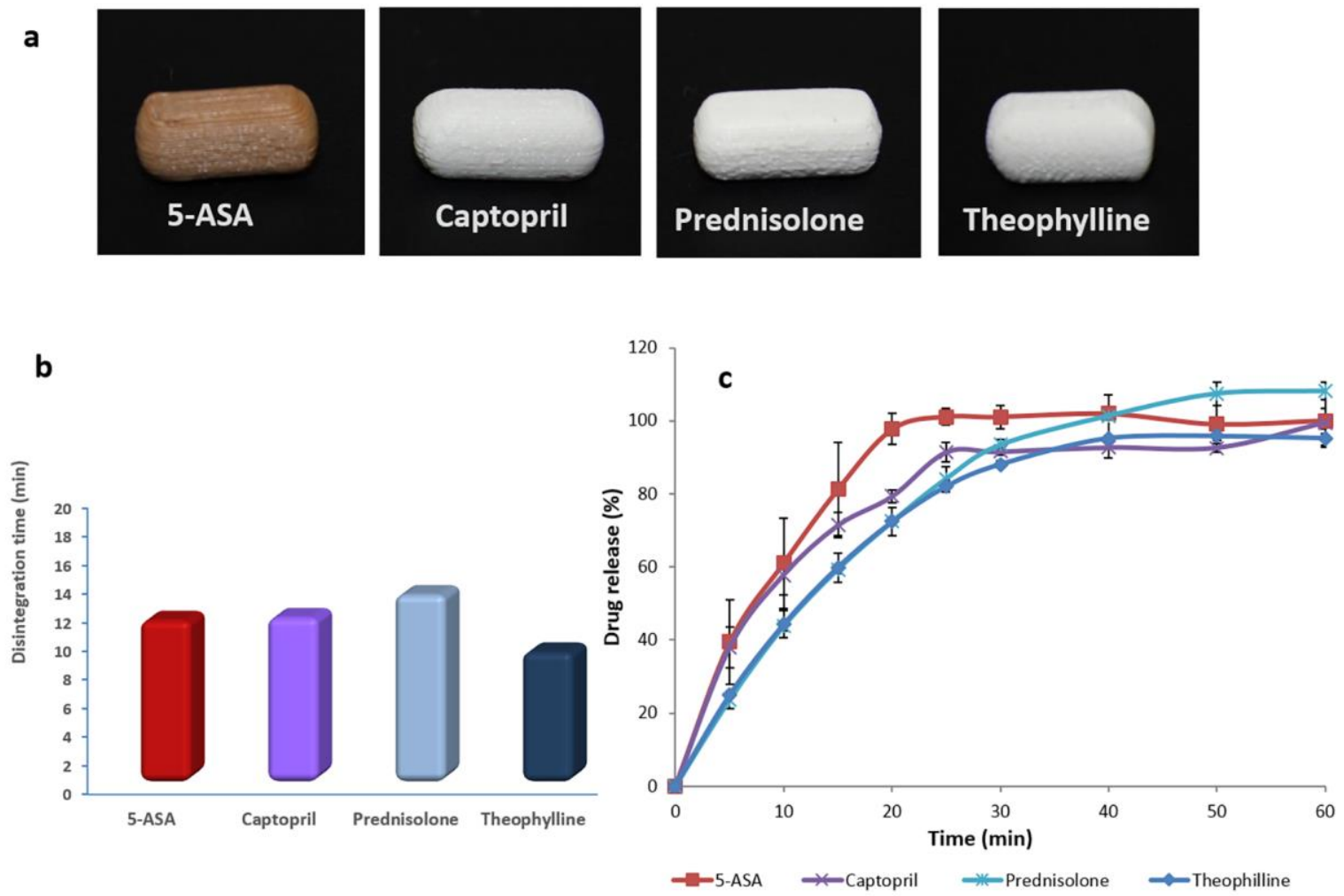

Fig. 8. (A) Photographs of 3D printed tablets containing the model drugs; 5-ASA, captopril, prednisolone or theophylline, (B) disintegration time for the different $3 \mathrm{~d}$ printed tablets $(n=6)$ and $(C)$ drug release from 3D printed Eudragit EPO tablets $(n=3)$.

It was possible to maintain the caplet shape for all model drugs (Fig. 8 a) with disintegration time of less than 15 minutes (Fig. 8b). The distinctive brown colour of 5-ASA tablet may suggest the degradation of 5-ASA. However, HPLC data and TGA did not showed a significant degradation. Such colour can attributed to the grey/pink colour of pure 5-ASA crystals (Comission, 2010). The in vitro release patterns from Eudragit EPO printed tablets indicated that the majority of the drug was released within $30 \mathrm{~min}$ (Fig. 8c). As the dissolution of all model drugs was carried out at sink condition, the drug release was mainly dictated by the dissolution rate of the polymer. At gastric $\mathrm{pH}$, the dimethylaminoethyl side chains of Eudragit EPO ionises leading to electrostatic repulsion between the cationic polymeric chains. Consequently, this increases the polymeric chain spaces thus allowing the dissolution of the polymer and drug release. All the different tablets released more than $85 \%$ of its drug content within 30 minutes. 


\section{Conclusions}

A novel approach based on the addition of a pharmaceutical grade non-melting filler (TCP) to allow a consistent flow from FDM 3D printer's nozzle and facilitate a reproducible 3D printing was presented. An optimal range of non-melting component of (20-50\%) within the filament composition enables the fabrication of well-defined caplets. Filaments produced via this approach were suitable for incorporating four model drugs of different physicochemical properties. HPLC indicated above $94 \%$ of drug contents remained intact in the tablet following the two thermal processes for theophylline, 5-ASA and prednisolone, whilst a significant drop in captopril content was observed and might be attributed to thermal degradation. The tablets fabricated possessed excellent mechanical strength and acceptable in-batch variations. The approach presented involving FDM 3D printing offers several advantages for developing personalised dose on demand. These include i) use of low cost printer and widely available and approved pharmaceutical ingredients, ii) suitability of different drug molecules, iii) significant improvement on morphology and mechanical resistance (friability), and iv) absence of postprinting finishing and drying steps.

\section{Acknowledgments}

The authors would like to thank UCLAN Innovation Team for this support and Mrs Reem Arafat for her help with graphics design.

\section{Supplementary data}

Fig. S1. Stress $(\varepsilon)$ moduli of TCP based filaments as a function of the strain $\left(\mathrm{T}=135^{\circ} \mathrm{C}, \omega=10 \mathrm{rad} \cdot \mathrm{s}-\right.$ $1)$. 


\section{References}

Andrews, G.P., Jones, D.S., Diak, O.A., McCoy, C.P., Watts, A.B., McGinity, J.W., 2008. The manufacture and characterisation of hot-melt extruded enteric tablets. Eur J Pharm Biopharm 69, 264-273.

Aprecia, 2014. Zipdose ${ }^{\circledR}$ technology.

Bruce, L.D., Shah, N.H., Malick, A.W., Infeld, M.H., McGinity, J.W., 2005. Properties of hot-melt extruded tablet formulations for the colonic delivery of 5-aminosalicylic acid. Eur. J. Pharm.

Biopharm. 59, 85-97.

Comission, B.P., 2010. Mesalazine monograph. The department of Health, London.

Enderle, J.D., Bronzino, J.D., Blanchard, S.M., 2005. Introduction to Biomedical Engineering. Elsevier Academic Press.

Fuh, J.Y.H., Lu, L., Tan, C.C., Shen, Z.X., Chew, S., 1999. Processing and characterising photo-sensitive polymer in the rapid prototyping process. J Mater Process Tech 89-90, 211-217.

GBIResearch, 2012. Oral drug delivery market report.

Ginsburg, G.S., Willard, H.F., 2009. Genomic and personalized medicine: foundations and applications. Translational research : the journal of laboratory and clinical medicine 154, 277-287. Goyanes, A., Buanz, A.B., Hatton, G.B., Gaisford, S., Basit, A.W., 2014a. 3D printing of modifiedrelease aminosalicylate (4-ASA and 5-ASA) tablets. Eur J Pharm Biopharm.

Goyanes, A., Buanz, A.B.M., Basit, A.W., Gaisford, S., 2014b. Fused-filament 3D printing (3DP) for fabrication of tablets. Int J Pharm 476, 88-92.

Goyanes, A., Chang, H., Sedough, D., Hatton, G.B., Wang, J., Buanz, A., Gaisford, S., Basit, A.W., 2015a. Fabrication of controlled-release budesonide tablets via desktop (FDM) 3D printing. Int J Pharm 496, 414-420.

Goyanes, A., Robles Martinez, P., Buanz, A., Basit, A.W., Gaisford, S., 2015b. Effect of geometry on drug release from 3D printed tablets. Int J Pharm 494, 657-663.

Goyanes, A., Wang, J., Buanz, A., Martinez-Pacheco, R., Telford, R., Gaisford, S., Basit, A.W., 2015c. 3D Printing of Medicines: Engineering Novel Oral Devices with Unique Design and Drug Release Characteristics. Mol Pharm 12, 4077-4084.

Hamad, K., Kaseem, M., Deri, F., Ko, Young G., 2016. Mechanical properties and compatibility of polylactic acid/polystyrene polymer blend. Materials Letters 164, 409-412.

Hamburg, M.A., Collins, F.S., 2010. The path to personalized medicine. The New England journal of medicine 363, 301-304.

Huang, F.-Y., 2012. Thermal Properties and Thermal Degradation of Cellulose Tri-Stearate (CTs). Polymers 4, 1012.

Huang, S.H., Liu, P., Mokasdar, A., Hou, L., 2013. Additive manufacturing and its societal impact: a literature review. Int J Adv Manuf Tech 67, 1191-1203.

Hwang, S., Reyes, E.I., Moon, K.-s., Rumpf, R.C., Kim, N.S., 2014. Thermo-mechanical Characterization of Metal/Polymer Composite Filaments and Printing Parameter Study for Fused Deposition Modeling in the 3D Printing Process. J. Electron. Mater. 44, 771-777.

Katstra, W.E., Palazzolo, R.D., Rowe, C.W., Giritlioglu, B., Teung, P., Cima, M.J., 2000a. Oral dosage forms fabricated by Three Dimensional Printing (TM). J. Control. Release 66, 1-9.

Katstra, W.E., Palazzolo, R.D., Rowe, C.W., Giritlioglu, B., Teung, P., Cima, M.J., 2000b. Oral dosage forms fabricated by Three Dimensional Printing ${ }^{\mathrm{TM}}$. J. Control. Release 66, 1-9.

Khaled, S.A., Burley, J.C., Alexander, M.R., Roberts, C.J., 2014a. Desktop 3D printing of controlled release pharmaceutical bilayer tablets. Int J Pharm 461, 105-111.

Khaled, S.A., Burley, J.C., Alexander, M.R., Roberts, C.J., 2014b. Desktop 3D printing of controlled release pharmaceutical bilayer tablets. Int J Pharm 461, 105-111.

Khaled, S.A., Burley, J.C., Alexander, M.R., Yang, J., Roberts, C.J., 2015a. 3D printing of five-in-one dose combination polypill with defined immediate and sustained release profiles. J. Control. Release $217,308-314$. 
Khaled, S.A., Burley, J.C., Alexander, M.R., Yang, J., Roberts, C.J., 2015b. 3D printing of tablets containing multiple drugs with defined release profiles. Int J Pharm 494, 643-650.

Khaled, S.A., Burley, J.C., Alexander, M.R., Yang, J., Roberts, C.J., 2015c. 3D printing of tablets containing multiple drugs with defined release profiles. Int J Pharm.

Liu, H.B., Chen, Y., Zhang, X.C., 2007. Characterization of anhydrous and hydrated pharmaceutical materials with $\mathrm{THz}$ time-domain spectroscopy. Journal of pharmaceutical sciences 96, 927-934.

Makerbot, 2013. Replicator 2X Experimental 3D Printer User Manual., http://downloads.makerbot.com/replicator2x/MakerBot Replicator2X UserManual Eng.pdf Marketsandmarkets, 2013. Drug delivery technology market.

McLean, S., Sheikh, A., Cresswell, K., Nurmatov, U., Mukherjee, M., Hemmi, A., Pagliari, C., 2013. The Impact of Telehealthcare on the Quality and Safety of Care: A Systematic Overview. Plos One 8. Morita, R., Honda, R., Takahashi, Y., 2000. Development of oral controlled release preparations, a PVA swelling controlled release system (SCRS): I. Design of SCRS and its release controlling factor. J. Control. Release 63, 297-304.

Nishiwaki, A., Watanabe, A., Higashi, K., Tozuka, Y., Moribe, K., Yamamoto, K., 2009. Molecular states of prednisolone dispersed in folded sheet mesoporous silica (FSM-16). Int J Pharm 378, 17-22. Overgaard, A.B., Hojsted, J., Hansen, R., Moller-Sonnergaard, J., Christrup, L.L., 2001. Patients' evaluation of shape, size and colour of solid dosage forms. Pharm World Sci 23, 185-188.

Pham, D.T., Gault, R.S., 1998. A comparison of rapid prototyping technologies. Int J Mach Tool Manu 38, 1257-1287.

Pietrzak, K., Isreb, A., Alhnan, M.A., 2015. A flexible-dose dispenser for immediate and extended release 3D printed tablets. Eur J Pharm Biopharm.

Pyrce Lewis, W.E., Rowe, C.W., Cima, M.J., Materna, P.A., 2011. System and method for uniaxial compression of an article, such as a three-dimensionally printed dosage form. Patent 0198677. Sabzevari, A., Adibkia, K., Hashemi, H., Hedayatfar, A., Mohsenzadeh, N., Atyabi, F., Ghahremani, M.H., Dinarvand, R., 2013. Polymeric triamcinolone acetonide nanoparticles as a new alternative in the treatment of uveitis: in vitro and in vivo studies. Eur J Pharm Biopharm 84, 63-71.

Sanderson, K., 2015. 3D printing: the future of manufacturing medicine? Pharm. J. 7865.

Sandler, N., Salmela, I., Fallarero, A., Rosling, A., Khajeheian, M., Kolakovic, R., Genina, N., Nyman, J., Vuorela, P., 2014. Towards fabrication of 3D printed medical devices to prevent biofilm formation. Int J Pharm 459, 62-64.

Schiele, J.T., Quinzler, R., Klimm, H.-D., Pruszydlo, M.G., Haefeli, W.E., 2012. Difficulties swallowing solid oral dosage forms in a general practice population: prevalence, causes, and relationship to dosage forms. Eur. J. Clin. Pharmacol. 69, 937-948.

Shishu, Kamalpreet, Kapoor, V.R., 2010. Development of taste masked oral formulation of ornidazole. Indian J Pharm Sci 72, 211-215.

Skowyra, J., Pietrzak, K., Alhnan, M.A., 2015. Fabrication of extended-release patient-tailored prednisolone tablets via fused deposition modelling (FDM) 3D printing. Eur. J. Pharm. Sci. 68, 11-17. Tapan Parikh, S.S.G., Anuprabha Meena, Abu T.M. Serajuddin, 2014. Investigation of thermal and viscoelastic properties of polymers relevant to hot melt extrusion - III: Polymethacrylates and polymethacrylic acid based polymers. J. Excipients and Food Chem. 5, 9.

Tremblay, J., Hamet, P., 2013. Role of genomics on the path to personalized medicine. Metabolism 62 Suppl 1, S2-5.

Wang, C.C., Tejwani Motwani, M.R., Roach, W.J., Kay, J.L., Yoo, J., Surprenant, H.L., Monkhouse, D.C., Pryor, T.J., 2006. Development of near zero-order release dosage forms using three-dimensional printing (3-DP) technology. Drug development and industrial pharmacy 32, 367-376.

Yang, C., Yu, D.G., Pan, D., Liu, X.K., Wang, X., Bligh, S.W.A., Williams, G.R., 2016. Electrospun pHsensitive core shell polymer nanocomposites fabricated using a tri-axial process. Acta Biomater 35 , 77-86.

Yoo, J., Bradbury, T.J., BEBB, T.J., ISKRA, J., SURPRENANT, H.L., WEST, T.G., 2014. Three-dimensional Printing System and Equipment Assembly. Google Patents. 
Yu, D.-G., Branford-White, C., Yang, Y.-C., Zhu, L.-M., Welbeck, E.W., Yang, X.-L., 2009. A novel fast disintegrating tablet fabricated by three-dimensional printing. Drug Dev IndPharm 35, 1530-1536. Yu, D.G., Li, X.Y., Wang, X., Yang, J.H., Bligh, S.W.A., Williams, G.R., 2015. Nanofibers Fabricated Using Triaxial Electrospinning as Zero Order Drug Delivery Systems. ACS Appl. Mater. Interfaces 7, 1889118897.

Yu, D.G., Yang, X.L., Huang, W.D., Liu, J., Wang, Y.G., Xu, H., 2007. Tablets with material gradients fabricated by three-dimensional printing. Journal of pharmaceutical sciences 96, 2446-2456.

Yurekli, K., Krishnamoorti, R., Tse, M.F., McElrath, K.O., Tsou, A.H., Wang, H.C., 2001. Structure and dynamics of carbon black-filled elastomers. J Polym Sci B Polym Phys 39, 256-275. 


\section{List of Figures}

Fig. 1. Schematic illustration of the fabrication of immediate release 3D-printed tablet. (A) Materials mixture (drug, methacrylic polymer and TCP) are processed through HME to produce (B) a uniform filament. (C) Stereolithographic file is created via CAD software and (D) benchtop FDM 3D printer is used to (E) fabricate drug loaded immediate release tablet.

Fig. 2. Thermal analysis of Eudragit EPO based 3D printing filaments. (A) Thermal degradation profiles for different fillers screened for suitability with Eudragit EPO, (B) DSC thermograph for different plasticizer concentrations incorporated in Eudragit EPO filament, (C) DSC thermograph for different TCP concentrations (non-melting component) incorporated in the Eudragit EPO filament and (D) DSC thermograph of different 3D printed tablets containing the model drugs; 5-ASA, captopril, prednisolone or theophylline.

Fig. 3. Impact of TCP concentration on the morphology of Eudragit EPO filaments; (a) SEM images of filaments with no TCP, (b) SEM image of TCP alone and (c-f) SEM images of filament incorporating TCP at a ratio of $20,40,50$ or $60 \%$ respectively.

Fig. 4. Storage $\left(\mathrm{G}^{\prime}\right)$ and loss $\left(\mathrm{G}^{\prime \prime}\right)$ moduli of $\mathrm{CAP}$ based filaments as a function of the strain $\left(\mathrm{T}=135^{\circ} \mathrm{C}\right.$, $\left.\omega=10 \mathrm{rad} \cdot \mathrm{s}^{-1}\right)$.

Fig. 5. XRPD patterns of Eudragit EPO, TPC, model drugs and drug loaded filaments and 3D printed tablets for a) 5-ASA, b) captopril, c) prednisolone and d) theophylline.

Fig. 6. Thermal degradation profiles for the used model drugs, drug loaded filament and 3D printed tablet; a) 5ASA, b) captopril, c) prednisolone and d) theophylline.

Fig. 7. SEM images of $3 \mathrm{D}$ printed tablets containing theophylline; (A) surface morphology (B-D) cross-sections.

Fig. 8. (A) Photographs of 3D printed tablets containing the model drugs; 5-ASA, captopril, prednisolone or theophylline, (B) disintegration time for the different $3 \mathrm{~d}$ printed tablets $(\mathrm{n}=6)$ and $(\mathrm{C})$ drug release from 3D printed Eudragit EPO tablets $(n=3)$.

\section{List of tables}

Table 1. Summary of weight uniformity, drug content, friability, disintegration time and the dimensions of the different 3D printed tablets. 